\title{
Towards identification of an efficient set of natural diversity recovery catchments in the Western Australian wheatbelt
}

\author{
T.V. Walshe', S.A. Halse', N.L. McKenzie ${ }^{2}$ and N. Gibson ${ }^{2}$ \\ 'Centre of Excellence in Natural Resource Management, University of Western Australia, \\ 444 Albany Hwy, Albany, Western Australia 6330, Australia \\ Department of Conservation and Land Management. \\ P.O. Box 51 Waneroo, Western Australia 6946, Australia
}

\begin{abstract}
Prudent allocation of scarce conservation resources requires rigour in the identification of conservation areas. We sought to broadly identify areas within the wheatbelt that would efficiently represent assemblages derived from the biological survey considered susceptible to the threat of salinity. We inferred the spatial distribution of each assemblage's species richness using a simple interpolation procedure. After omitting assemblages considered not to be threatened by salinity, as well as those for which the interpolation procedure failed to discriminate areas of high and low richness, analyses were undertaken using 17 aquatic and 6 terrestrial assemblages. To gain an appreciation of the magnitude of resourcing required for different levels of representation, we described the number of subcatchments and the area required to satisfy a range of conservation targets, where targets were based on the number of species associated with each assemblage. Nearoptimal solutions were identified using a heuristic algorithm principally driven by a measure of irreplaceability for each of 829 subcatchments comprising the study area.

Results identified a subset of core areas for conservation investment that efficiently represented assemblage diversity. However, when on-ground management activities commence in each of the identified areas, field reconnaissance and verification will be necessary to account for localised variation in species richness and for vagaries in the distribution of remnant vegetation patches, wetlands and salinity risk. After canvassing limitations of the methodological approach, we conclude that the use of systematic planning tools involving heuristic algorithms provides a sound basis for estimating the extent and configuration of areas needed to satisfy specified conservation targets.
\end{abstract}

\section{INTRODUCTION}

Approximately $75 \%$ of the native vegetation of the wheatbelt region of Western Australia has been cleared for agriculture over the last 150 years (George at al., 1995). The viability of the region's biodiversity is threatened by a suite of processes, with habitat loss, fragmentation and salinisation associated with broad-scale land clearance considered especially important (Saunders of al., 1993; Kay it al., 2001; Cramer and Hobbs, 2002; Halse it al., 2003; McKenzie et al., 2003). Within the Southwest Agricultural Zone, it is estimated that 1.8 million ha of land are currently affected by salinity, and in the absence of intervention, 6 million ha are predicted to be affected by the time a new hydrological equilibrium is reached (Ferdowsian et al., 1996).

The scale of threats to the wheatbelt region's biodiversity and the high costs associated with their effective remediation demands prioritisation and rigour in the investment of public resources (Pannell, 2001; Possingham, 2001). Yet the prudent allocation of scarce conservation resources is a fundamental challenge to management agencies and the broader community (Burgman if al., 1993; Kristjanson and Hobbs, 2001). In an attempt to reduce the impact of salinisation on biodiversity (as well as agricultural productivity and rural infrastructure) the Western Australian government announced a Salinity Action Plan in 1996 (Anonymous 1996). One of the recommendations of the plan was that a biological survey of the wheatbelt be undertaken to assist in selecting catchments of high biodiversity value, termed originally Biodiversity Recovery Catchments but now referred to as natural diversity recovery catchments, where public money would be invested to control salinisation and maintain conservation values.

The biological survey revealed substantially 
greater biodiversity than previously recorded (Keighery, 2001). The terrestrial survey of 304 quadrats found 2,878 species, which on the basis of patterns of co-occurrence could be grouped into 17 assemblages after exclusion of singletons (McKenzie et. al., 2004). The aquatic survey conducted at 197 wetlands found 1,887 species which, after excluding singletons, were characterised by 19 assemblages (Halse et al., 2004). The number of species comprising any one assemblage varied considerably.

The focus of analyses presented here is efficient capture of the richness of wetland and terrestrial assemblages considered susceptible to the threat of salinisation in notional natural diversity recovery catchments. The taxonomic breadth included in the biological survey (Halse et al., 2004; McKenzie et al., 2004) suggests that conservation targets might better utilise assemblages as the entities of interest rather than other surrogates such as vegetation type or abiotic gradients. Distal surrogates may be poorly correlated with many taxonomic groups (Ferrier and Watson, 1997; Moritz et al., 2001). Given that assemblages show strongly nested patterns in their species composition (Table 6 in McKenzie et al., 2004; Table 4 in Halse et al., 2004) species richness can be regarded as a reasonable surrogate for composition.

Some of the wheatbelt's outstanding biological diversity had already been identified and protected in six natural diversity recovery catchments using a combination of preliminary survey results and expert opinion (Department of Environment, 2003; Figure 1). However, a more formal analysis was required to determine which other areas in the wheatbelt might best complement these existing recovery catchments in meeting conservation goals.

Species richness data can be used for conservation planning in several ways. A simple and unambiguous method is to conserve the richest exemplars of each assemblage (see Figure 2 in Halse et al., 2004). Although attractive in its simplicity and transparency, this approach is unlikely to provide an efficient outcome. A better outcome may be obtained if the 'richest exemplar' criterion is relaxed and consideration is given to areas where reasonably high richness values for two or more assemblages coincide (e.g. see Figures 11 and 12 in McKenzie et al., 2004). In this paper we adopt the objective of selecting a recovery catchment system that has a minimum representation threshold for each assemblage, where we use the number of species associated with each assemblage as the basis for determining minimum representation. We seek to achieve the objective in an efficient way such that our objective is achieved with as few as possible new areas added to the current system of natural diversity recovery catchments.

A simple hypothetical example illustrates the ap- proach and formulation of the problem, and the inefficiency of an approach based on richest exemplars. Suppose the biota of a region comprises $n=$ 120 species that are characterised by $k=3$ assemblages. The number of species associated with Assemblages $\mathrm{A}, \mathrm{B}$ and $\mathrm{C}$ is $n_{4}=40, n_{\beta}=20$ and $n_{c}=$ 60. There are $m=6$ candidate sites for recovery catchment selection. The assemblage-specific species richness at each of the six sites is described in a site-by-assemblage matrix $(m \times k)$ with elements $a_{,}$, for $i=1, \ldots . m$ and $j=1, \ldots . k$, as shown in Table 1 . The vector $X$ with dimension $m$ and elements $x$. describes whether or not a site is included in the recovery catchment system, where

$x_{i}=\left\{\begin{array}{l}1 \text { if site } i \text { is included in the recovery catchment system } \\ 0 \text { otherwise }\end{array}\right.$

Now, suppose we set minimum summed species richness representation targets for each assemblage $j$ equivalent to its corresponding number of associated species, $n_{i}$. That is, the summed species richness target for Assemblage $\mathrm{A}=n_{A}=40$. The targets for Assemblages B and C are 20 and 60, respectively. Our objective is to find the minimum set of sites that will simultaneously satisfy the three targets.

More formally, the problem can be stated as,

$$
\begin{aligned}
& \text { minimise } \sum_{i=1}^{m} x_{i}, \\
& \text { subject to the three constraints, } \\
& \sum_{i=1}^{m} a_{i j} x_{i} \geq 40 \text {, for } j=\text { Assemblage } \mathrm{A}, \\
& \sum_{i=1}^{m} a_{i j} x_{i} \geq 20 \text {, for } j=\text { Assemblage } \mathrm{B} \text {, and } \\
& \sum_{i=1}^{m} a_{i j} x_{i} \geq 60 \text {, for } j=\text { Assemblage } \mathrm{C} .
\end{aligned}
$$

After some consideration, it is reasonably easy to see from Table 1 that the minimum number of sites that will satisfy the objective is two - Sites 3 and 5 . Note that although Site 1 contained the greatest total species richness, it does not form part of the minimum set. Note also that if we had used the richest exemplar criterion as the basis for site selection (Site 4 for Assemblage A, Site 5 for Assemblage B, and Site 6 for Assemblage C) the target would not be achieved for any of the assemblages, despite inclusion of one more site than the minimum set solution.

It is important to emphasise that defining summed species richness targets on the basis of $n$, does not imply that all species associated with an assemblage are represented in the recovery catchment system. For example, if $50 \%$ of the Assemblage $C$ species at Site 3 also occur at Site 5 
Table 1 Site-by-assemblage matrix for a hypothetical example of a minimum set problem. The elements of the matrix refer to species richness values for each assemblage at each site. See text for details.

Site 1 Site 2 Site 3 Site 4 Site 5 Site 6

\begin{tabular}{lrrrrrr}
\hline Assemblage A & 25 & 0 & 25 & 30 & 15 & 0 \\
Assemblage B & 0 & 10 & 5 & 10 & 15 & 5 \\
Assemblage C & 50 & 40 & 30 & 5 & 30 & 55 \\
Total & 75 & 50 & $\mathbf{6 0}$ & $\mathbf{4 5}$ & $\mathbf{6 0}$ & $\mathbf{6 0}$ \\
\hline
\end{tabular}

(see Table 1) the total number of $C$ species represented in the minimum set system is $30+(0.5$ $\times 30)=45$. If data describing the individual spatial distributions of all 120 species throughout the region of our hypothetical example were available, the minimum set analysis could be undertaken at the species-level rather than the assemblage-level. However, collation of such data is commonly impractical, making a coarse approach necessary (Burgman and Lindenmayer, 1998; Ferrier, 2002).

Targets defined as multiples of $n$ can be increased to reduce the effect of analyses undertaken at the assemblage-level compromising the representation of species-level diversity. Instead of setting assemblage-specific targets equivalent to $1 \times n$, a larger multiplier can be nominated. For targets equivalent to $2 \times n$, the threshold summed species richness for Assemblages A, B and C is 80, 40 and 120, respectively. Again, after consideration of
Table 1, the minimum set for the $2 \times n$ targets can be seen to be five - Sites 1, 2, 3, 4 and 5 .

The solution to the simple example provided in Table 1 can be solved by inspection. For larger data sets, the computational task can be formulated as an optimisation linear programming problem, with the objective function of minimising the set of selected sites subject to a set of constraints, as defined above. However, for most real-life data sets, linear programming is not practical because either the number of constraints is too large to allow an optimum solution to be found (Garey and Johnson, 1979) or the size of the data set makes the time to arrive at a solution cost-prohibitive (Possingham it al., 2000).

An alternative that involves some loss of optimality is a heuristic approach (Pressey et al., 1996). Essentially, heuristic methods rank each candidate site according to some criteria expressed as an algorithm and select the highest ranking site iteratively until the target(s) is achieved. Early examples of the approach include work on remnant mallee in South Australia (Margules and Nicholls, 1987), forest in southern New South Wales (Bedward et al., 1992; Belbin, 1992; Nicholls and Margules, 1993), vertebrates in subtropical northwestern Australia (Woinarski, 1992) and semiarid lands in western New South Wales (Pressey and Nicholls, 1989).

The criteria employed for iterative site selection in these early examples commonly involved

Table 2 The number of species associated with each assemblage ( $n$ ), the assemblage-specific $15 \%$ exemplar thresholds used to omit elements in the subcatchment-by-assemblage matrix, and example summed species richness (SSR) targets used in minimum set analyses.

\begin{tabular}{|c|c|c|c|c|c|}
\hline \multirow[b]{2}{*}{ Assemblage } & \multirow[b]{2}{*}{$n_{j}$ species } & \multirow[b]{2}{*}{$15^{\circ} \%$ threshold } & \multicolumn{3}{|c|}{ Example SSR targets } \\
\hline & & & $1 \times n_{i}$ & $2 \times n_{i}$ & $3 \times n_{j}$ \\
\hline $\mathrm{T} 1 \_2$ & 277 & 42 & 277 & 554 & 831 \\
\hline $\mathrm{T} 6$ & 112 & 17 & 112 & 224 & 336 \\
\hline $\mathrm{T} 7$ & 16 & 2 & 16 & 32 & 48 \\
\hline TSA & 118 & 18 & 118 & 236 & 354 \\
\hline T16 & 130 & 20 & 130 & 260 & 390 \\
\hline T27_33 & 239 & 36 & 2.39 & 478 & 717 \\
\hline$W 1^{-}$ & 27 & 4 & 27 & 54 & 81 \\
\hline W2 & 106 & 16 & 106 & 212 & 318 \\
\hline W3 & 61 & 9 & 61 & 122 & 183 \\
\hline W4 & 62 & 9 & 62 & 124 & 186 \\
\hline W5 & 64 & 10 & 64 & 128 & 192 \\
\hline W6 & 35 & 5 & 35 & 70 & 105 \\
\hline W8 & 70 & 11 & 70 & 140 & 210 \\
\hline W9 & 30 & 5 & 30 & 60 & 90 \\
\hline W10 & 100 & 15 & 100 & 200 & 300 \\
\hline W11 & $H$ & 7 & 44 & 88 & 132 \\
\hline W12 & 6.3 & 9 & 63 & 126 & 189 \\
\hline W1.3 & 68 & 10 & 68 & 136 & 204 \\
\hline W14 & 37 & 6 & 37 & 74 & 111 \\
\hline Wlo & 51 & 8 & 51 & 102 & 153 \\
\hline W17 & 89 & 13 & 89 & 178 & 267 \\
\hline W18 & 84 & 13 & 84 & 168 & 252 \\
\hline W20 & 74 & 11 & 74 & 148 & 222 \\
\hline
\end{tabular}


measures of uniqueness or rarity applied to presence-absence data, whereby sites were sequentially added to a reserve system according to the highest uniqueness or rarity score associated with unrepresented features. The algorithm is 'greedy' in that it seeks to maximise the rate of progress toward achievement of the target at each iteration. Greedy algorithms inevitably result in a loss of optimality in the minimum set solution (Possingham et al., 2000). The extent of the departure from optimality will depend on interactions between the specific criteria used in the algorithm, targets, and the characteristics of the data (Pressey et al., 1997, 1999).

Although it cannot entirely remove the problem of sub-optimality, development of the concept of a site's 'irreplaceability' has provided distinct improvement in heuristic approaches to conservation planning (Pressey et al., 1994). In defining irreplaceability, Pressey et al. (1994) identified two related properties: (a) the likelihood a candidate site will be required as part of a conservation reserve system that achieves the set of targets, and (b) the extent to which the options for achieving the set of targets are reduced if the site is made unavailable for conservation.

Ferrier et al. (2000) refined the definition of irreplaceability and developed a statistical approach to its prediction. Advantages of the irreplaceability index include its flexibility in conservation planning through transparent provision of alternative sites where minimum set solutions are deemed unsuitable or unavailable for conservation. Also, the index can be computed quickly for use in real-time planning applications (Pressey, 1999; Ferrier et al., 2000).

What specific targets should apply to the Western Australian wheatbelt? While the overarching aspirational biodiversity goal of the Salinity Investment Framework is 'to protect, conserve and, where necessary and possible, restore Western Australia's natural biodiversity' (Department of Environment, 2003), the extent of a recovery catchment system's regional coverage is constrained by acquisition and maintenance costs. Analyses undertaken here vary assemblage-specific summed species richness targets from $0.2 \times n_{j}$ to $3.0 \times n_{j}$ to explore the number of sites needed in a recovery

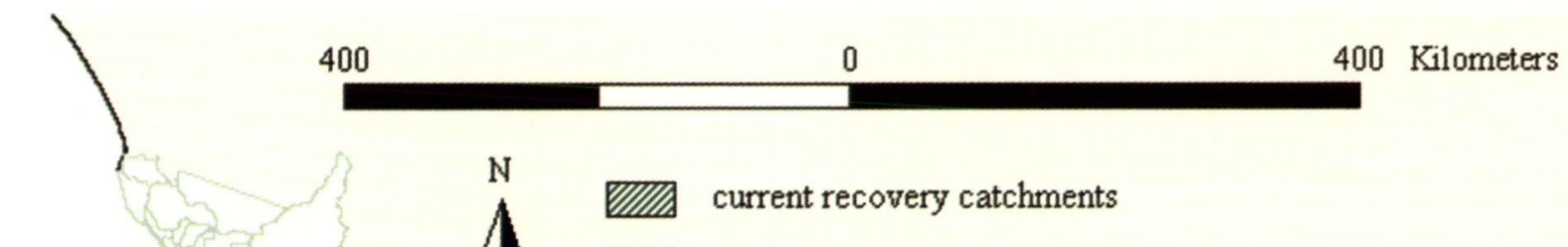

Geraldton

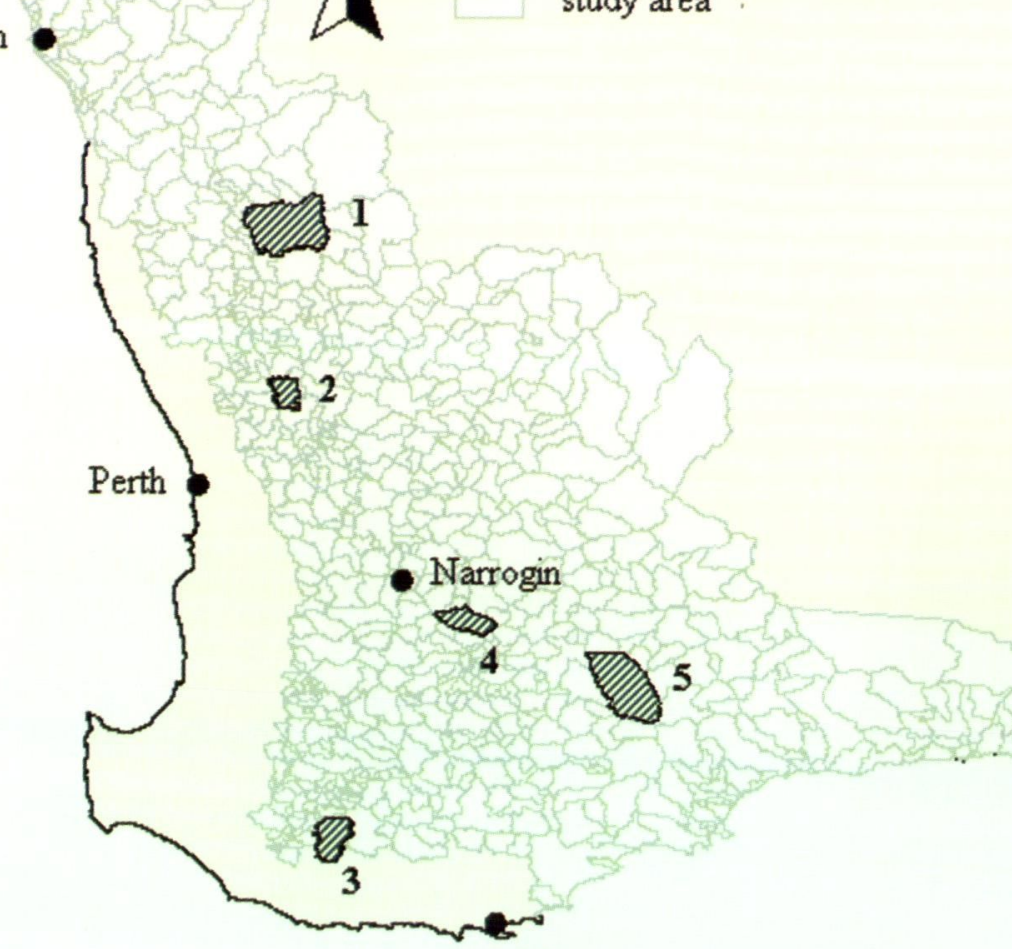

study area

Albany

Figure 1 Current natural diversity recovery catchments. Each catchment comprises one or more of the 829 subcatchments contained within the study area. 1 = Buntine-Marchagee, 2 = Drummond, 3 = Muir Unicup, 4 $=$ Toolibin, 5 = Lake Bryde, 6 = Lake Warden. 
catchment system to satisfy progressively more comprehensive conservation goals.

\section{METHODS}

Because salinisation is the principal threatening process motivating the identification of Natural Diversity Recovery Catchments, hydrological boundaries are a logical basis for defining sites. Here, we used subcatchments as candidate sites for selection. A polygon delineating an approximate $218000 \mathrm{~km}^{2}$ study area was used to clip a national map of subcatchment boundaries (Geoscience Australia, 2000) resulting in the demarcation of 829 candidate sites (Figure 1). The size of subcatchments varied, with the largest being $4583 \mathrm{~km}^{2}$ and the median $139 \mathrm{~km}^{2}$. Subcatchment boundaries used in analyses are hierarchically organised within higherorder hydrological units described by catchments and basins (Geoscience Australia, 2000).

Not all the assemblages derived from the biological survey data are threatened by salinisation. McKenzie it al. (2004) concluded that the 10 terrestrial assemblages centred on or extending across upland sandplain and laterite surfaces are unlikely to be significantly affected by salinity (assemblages T8b, T9, T10_12, T13_15, T17_18, T19, T20, T21, T22_26 and T34). Given that the goal of Natural Diversity Recovery Catchments is abatement of the threat of salinisation, we chose to exclude these assemblages from our analysis. All wetland assemblages were assumed to be adversely affected by salinisation.

The customised software package, C-Plan version 3.06 (New South Wales National Parks and Wildlife Service, 1999), was used to derive minimum set solutions from irreplaceability values for varying targets. Although it can be used independently of a Geographic Information System, all analyses were undertaken with C-Plan as an extension of ArcView version 3.2a (ESRI, 1992). In the context of the problem to be solved here, the key data requirement for C-Plan is a subcatchment-by-assemblage matrix, the elements of which describe richness values for each assemblage at each subcatchment.

Elements of the subcatchment-by-assemblage matrix were derived from results of the biological survey. The survey provided point data collected at 197 wetlands for aquatic assemblages and 304 quadrats for terrestrial assemblages. We avoided an analysis using these raw point data because the stratification employed in the sampling strategies was biased (Mckenzie et al., 2004; Halse ot al., 2004). Even where data underpinning reserve selection is collected without sampling bias, a trade-off exists in the choice of using the raw point data or applying a spatial model to predict the distribution of ecological entities (or abiotic surrogates) of interest throughout the study area (Pressey of al.,
2000; Ferrier, 2002; Peterson it al., 2002). A pointbased approach effectively reduces the set of candidate sites to those in which sampling units occur (Gladstone and Davis, 2003; Loiselle if al., 2003) but may be preferable where there is notable bias or error in an alternative involving spatial modelling (Freitag it al., 1998). Our approach was to use a simple spatial model to interpolate species richness from point data and assess the validity of reported trends using field-based knowledge of underlying environmental gradients.

For the terrestrial survey, the study area was divided into 24 survey areas (see Figure 1 in Mckenzie it al., 2004). Within each survey area, a quadrat was placed at each component of the landscape's geomorphic profile. Because assemblages varied in the strength of their association with specific geomorphic components, species richness of an assemblages was expected to vary among quadrats within a survey area. Thus, the distribution of an assemblage across the study area was inferred by using, from each of the 24 survey areas, only the quadrat in which the maximum species richness was recorded for that assemblage to define $x-y-z$ (latitude-longitudemaximum richness) values (Table 8 in McKenzie of al., 2004). For aquatic systems, the 197 wetlands surveyed (see Figure 1 in Halse et al., 2004) were grouped into 24 clusters of adjacent wetlands that represented the range of wetland types occurring in that locality. For each of the clusters, the wetland with maximum species richness for each assemblage provided the z-value and the geographic centroid of the cluster defined $x-y$ coordinates.

Coordinates forming the vertices of a minimum convex polygon encompassing known z-values varied between assemblages and did not extend to the periphery of the study area. We addressed this limitation by extending the vertices of each assemblage's minimum convex polygon to the extremities of the study area through estimation of richness values at 15 fixed extrapolated points. Extrapolated richness values for each assemblage at each of these $15 x-y$ coordinates were calculated using the three nearest known $x-y-z$ values, with a linear weighting inversely proportional to distance. The locations of known and extrapolated =-values forming the basis of inferred richness trends for each assemblage are provided in Appendix 1.

A continuous surface for each assemblage was derived through conversion of known and extrapolated $x-y-z$ values to a triangulated irregular network (TIN). TINs were converted to floating point grids with cell size $5 \mathrm{~km} \times 5 \mathrm{~km}$. The richness value of the cell corresponding to the centroid of each subcatchment was then used to assign elements of the subcatchment-by-assemblage matrix (Appendix 1). The TIN-based interpolation worked 
best for assemblages restricted to one or two geographic centres of high richness. On the basis of field experience and knowledge relating species patterns to broad environmental gradients, it was considered that most interpolated surfaces provided reasonable approximation of trends in assemblage richness and provided a superior basis for site selection compared to use of point data. Exceptions included the granite outcrop associated assemblages T3_5 (McKenzie et al., 2004) and W21, and the patchily distributed assemblage W7 (Halse et al., 2004), where the interpolation procedure distinctly failed to discriminate areas of high and low richness. These three assemblages were omitted from analyses, leaving 6 terrestrial and 17 wetland assemblages and a subcatchment-by-assemblage matrix of dimensions $829 \times 23$.

Extrapolation of richness trends to the periphery of the study area was considered appropriate for wetland assemblages. However, for the six terrestrial assemblages, we regarded extrapolation to portions of the south coast as inappropriate because of distinct contrasts in the physiography and biota of the Fitzgerald region and its immediate surrounds. For these subcatchments, terrestrial assemblage richness was denoted as zero in the subcatchment-by-assemblage matrix (Appendix 1).

Natural diversity recovery catchment selection for multiple features could result in relatively poor exemplars making up a substantial proportion of the summed species richness of some assemblages. To prevent this, and acknowledging that the interpolated surface for each assemblage provided a coarse description of richness trends across the landscape, we included in the analysis only subcatchments with moderate to high richness. For each assemblage, we assigned zero values in the input matrix for any subcatchments where the interpolation procedure reported richness values less than $15 \%$ of $n$. For example, for the assemblage W10 $(n=100)$, all subcatchments where the inferred richness value was less than 15 were denoted zero in the subcatchment-by-assemblage matrix (see Table 2).

Using the matrix thus obtained, we sought to identify the minimum set of subcatchments for targets varying from $0.2 \times n$ to $3.0 \times n_{i}$ to ascertain (a) qualitative changes in the spatial pattern of selected subcatchments to assess the sensitivity of results to varying targets; and (b) a broad appreciation of the number of subcatchments required to achieve progressively more comprehensive conservation goals. Examples of assemblage-specific $n_{i}$-related targets are shown in Table 2.

For all targets, the starting point of application of the heuristic algorithm was the mandatory inclusion of current Natural Diversity Recovery Catchments in the 'minimum' set (Figure 1). A variety of rules can be nominated in the heuristic algorithm (Pressey of al., 1997). Here, all C-Plan analyses used an algorithm comprising three rules:

Rule 1: Select the site with the highest summed irreplaceability

Rule 2: Select the site with the greatest contribution value

Rule 3: Randomly select among the tied sites

At each iteration a single subcatchment was selected using the first specified rule. Where sites were tied, the subsequent rule was employed.

Ferrier of al. (2000) suggests that for problems involving multiple targets, the index 'summed irreplaceability' performs better than simple irreplaceability. The index for site $i$ is simply the sum of single assemblage irreplaceabilities, $\operatorname{Irr}_{i j}$ estimated separately for each assemblage $j$. That is,

$$
S u m I r r_{i}=\sum_{j=1}^{k} I r r_{i j}
$$

In the context of analyses undertaken here, 'greatest contribution value' refers to the site having the highest number of under-represented assemblages that would be fully represented with its notional inclusion in the natural diversity recovery catchment system (Pressey et al., 1997). Summed irreplaceability and contribution value are not static indices in absolute or relative terms but change as the analysis proceeds and subcatchments are added to the recovery catchment system. Values are recalculated at each iteration. An illustration of the changes in summed irreplaceability with iteration number for the target $2.0 \times n$ is provided in Figure 2.

In specifying conservation targets, a raft of stakeholder judgments needs to be made regarding ecological adequacy, social acceptability and economic affordability. To provide an example of the detail provided by analyses undertaken, we assume this process resolves that a constraint is identified such that the final natural diversity recovery catchment system can be no larger than a doubling of the number of subcatchments contained within currently designated natural diversity recovery catchments (Figure 1). In total, 46 subcatchments make up the current system of natural diversity recovery catchments.

\section{RESULTS}

A system confined to the current recovery catchments was found to fail in the achievement of the smallest target for which analyses were undertaken, $0.2 \times n$. Figure 3 shows the number of subcatchments and corresponding area needed for targets equivalent to $0.2 \times n$ to $3.0 \times n_{\text {j. }}$. For $0.2 \times n$, the number of additional subcatchments required was four, comprising an area of $3722 \mathrm{~km}^{2}$. For $3.0 \times$ $n, 76$ additional subcatchments were required to satisfy the target for all assemblages, involving an 
Table 3 Summary of summed species richness (SSR) results for the target $2 \times n$. Full details are provided in Appendix 2 .

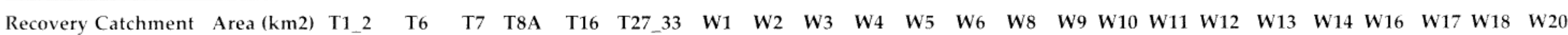

\begin{tabular}{|c|c|c|c|c|c|c|c|c|c|c|c|c|c|c|c|c|c|c|c|c|c|c|c|c|}
\hline \multicolumn{25}{|l|}{ Current } \\
\hline Buntine-Marchagee & 1794.2 & 0 & 0 & 0 & 579 & 0 & 0 & 0 & 0 & 0 & 0 & 453 & 223 & 0 & 0 & 0 & 60 & 0 & 399 & 320 & 0 & 0 & 0 & 40 \\
\hline Drummond & 359.1 & 0 & 0 & 0 & 51 & 0 & 39 & 4 & 0 & 0 & 18 & 36 & 21 & 15 & 0 & 0 & 0 & 0 & 24 & 11 & 0 & 16 & 0 & 0 \\
\hline Lake Bryde & 1919.6 & 0 & 0 & 0 & 358 & 0 & 0 & 58 & 0 & 0 & 0 & 239 & 135 & 67 & 21 & 194 & 0 & 0 & 249 & 84 & 0 & 0 & 0 & 123 \\
\hline Lake Warden & 1866.6 & 0 & 0 & 0 & 0 & 100 & 0 & 0 & 0 & 20 & 24 & 109 & 87 & 73 & 69 & 0 & 0 & 0 & 90 & 0 & 0 & 56 & 27 & 0 \\
\hline Muir Unicup & 547.6 & 0 & 0 & 0 & 215 & 0 & 659 & 0 & 0 & 0 & 0 & 363 & 188 & 207 & 99 & 0 & 0 & 0 & 204 & 0 & 142 & 423 & 386 & 130 \\
\hline Toolibin & 480.7 & 0 & 0 & 0 & 270 & 0 & 0 & 0 & 0 & 0 & 0 & 162 & 125 & 0 & 20 & 0 & 0 & 0 & 180 & 40 & 0 & 0 & 0 & 0 \\
\hline Subtota & 6967.8 & 0 & 0 & 0 & 1473 & 100 & 698 & 62 & 0 & 20 & 42 & 1363 & 779 & 363 & 209 & 194 & 60 & 0 & 1146 & 455 & 142 & 494 & 413 & 293 \\
\hline
\end{tabular}

Proposed

Avon

Blackwood

Esperence Coast

$4250.6-10-0-0 \quad 170$

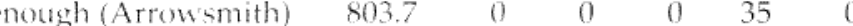

$\begin{array}{llllll}\text { Greenough (Hutt) } & 1890.6 & 0 & 89 & 13 & 219\end{array}$

$\begin{array}{llllllll}\text { Greenough (Irwin) } & 567.0 & 0 & 0 & 6 & 44 & 0\end{array}$

$\begin{array}{lllllll}\text { Murchison } & 2247.8 & 0 & 36 & 7 & 87 & 0\end{array}$

Ninghan

Yarra Yarra

$\begin{array}{rrrrrr}670.3 & 54 & 0 & 2 & 50 & 0\end{array}$

87503

0

$\begin{array}{lllllll}\text { Subtotal } & 24746.3 & 562 & 225 & 117 & 1354 & 170\end{array}$

$\begin{array}{rrrrrrrrrrrrrrrrrrr}0 & 0 & 0 & 0 & 0 & 139 & 99 & 0 & 0 & 0 & 48 & 0 & 128 & 113 & 0 & 0 & 0 & 0 \\ 152 & 4 & 0 & 0 & 0 & 119 & 89 & 46 & 35 & 0 & 0 & 0 & 124 & 6 & 17 & 64 & 0 & 44 \\ 0 & 0 & 0 & 104 & 39 & 360 & 236 & 192 & 169 & 30 & 0 & 0 & 238 & 0 & 132 & 108 & 14 & 0 \\ 0 & 0 & 17 & 0 & 0 & 34 & 20 & 0 & 0 & 0 & 0 & 9 & 26 & 18 & 0 & 16 & 0 & 26 \\ 0 & 4 & 130 & 0 & 54 & 149 & 79 & 63 & 20 & 0 & 0 & 0 & 69 & 51 & 0 & 54 & 0 & 152 \\ 0 & 0 & 16 & 0 & 0 & 33 & 16 & 0 & 0 & 0 & 7 & 9 & 18 & 17 & 0 & 0 & 0 & 17 \\ 0 & 0 & 51 & 0 & 21 & 58 & 31 & 25 & 5 & 0 & 0 & 0 & 27 & 21 & 0 & 14 & 0 & 62 \\ 0 & 0 & 0 & 0 & 0 & 19 & 21 & 0 & 0 & 0 & 16 & 0 & 24 & 22 & 0 & 0 & 0 & 0 \\ 0 & 0 & 0 & 0 & 0 & 296 & 189 & 0 & 0 & 0 & 138 & 115 & 316 & 253 & 0 & 0 & 0 & 176 \\ 152 & 8 & 214 & 104 & 114 & 1207 & 780 & \mathbf{3 2 6} & \mathbf{2 2 9} & \mathbf{3 0} & \mathbf{2 0 9} & \mathbf{1 3 2} & \mathbf{9 7 0} & \mathbf{5 0 1} & \mathbf{1 4 9} & \mathbf{2 5 6} & \mathbf{1 4} & 477\end{array}$

TOTAL SSR $\quad 562 \quad 225 \quad 117 \quad 2828 \quad 270$

$\begin{array}{llllllllllllllllll}849 & 70 & 214 & 124 & 156 & 2570 & 1560 & 689 & 438 & 224 & 269 & 132 & 2115 & 956 & 291 & 751 & 427 & 770\end{array}$

$\begin{array}{llllllllllllllllllllllll}\text { Target } & 554 & 224 & 32 & 236 & 260 & 478 & 54 & 212 & 122 & 124 & 128 & 70 & 140 & 60 & 200 & 88 & 126 & 136 & 74 & 102 & 178 & 168 & 148\end{array}$

$\begin{array}{llllllllllllllllllllllll}{ }_{0}^{\circ} \text { of Target } & 101 & 100 & 366 & 1198 & 104 & 178 & 130 & 101 & 102 & 126 & 2008 & 2228 & 492 & 730 & 112 & 306 & 105 & 1556 & 1292 & 286 & 422 & 254 & 520\end{array}$ 
Summed Irrepaceability (Ranked)

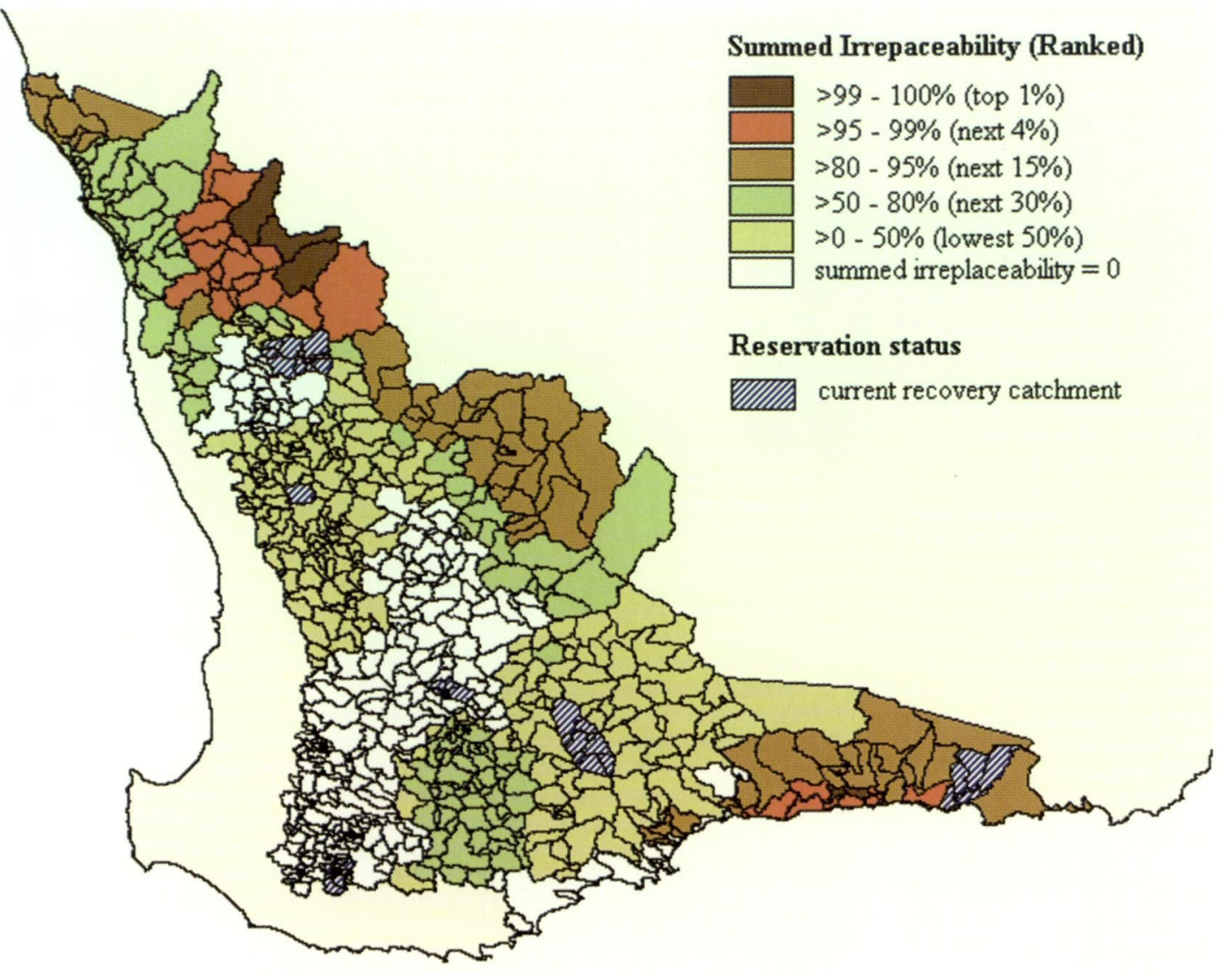

(a) Summed Irrepaceability (Ranked)

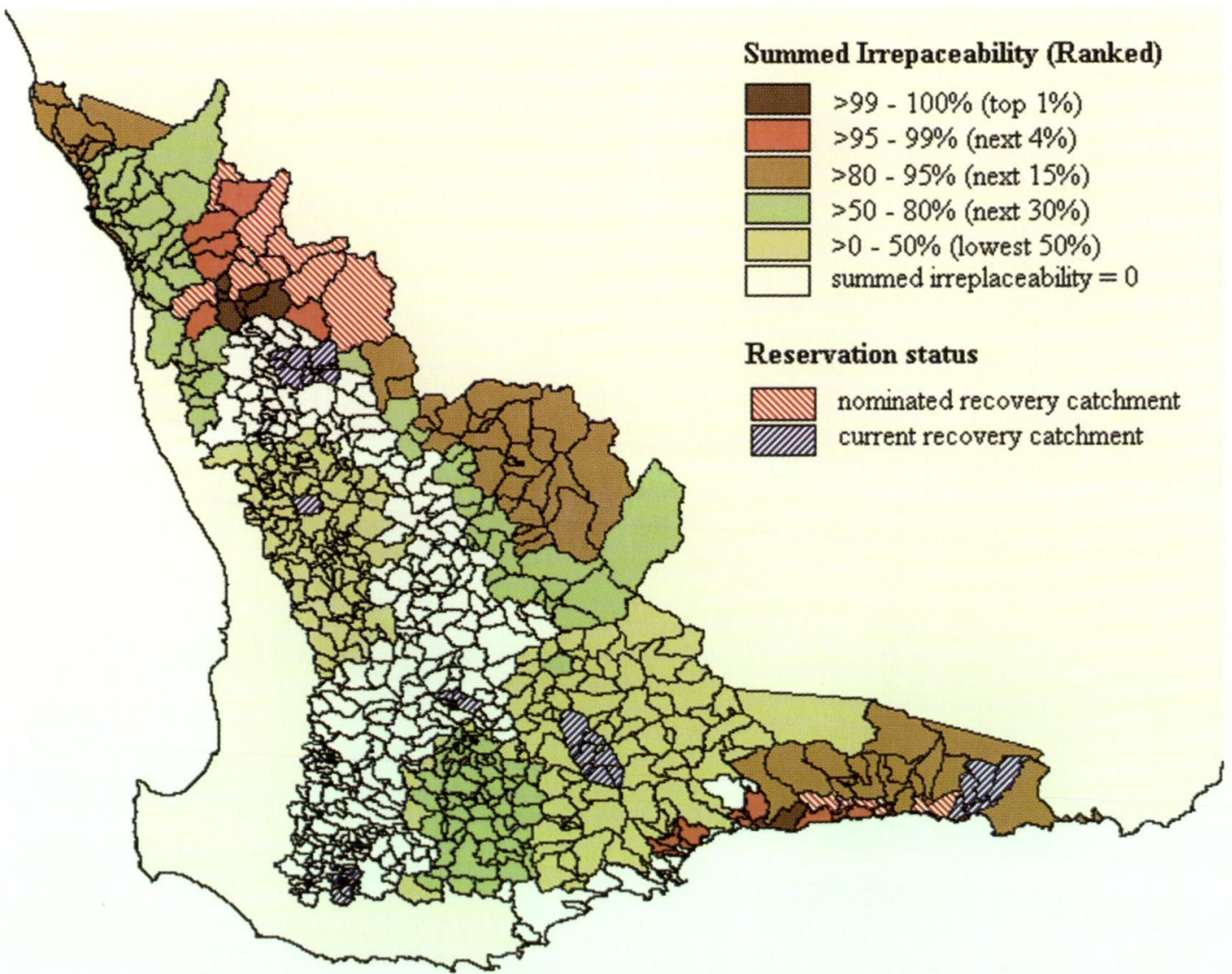

(b)

Figure 2 Example of relative summed irreplaceability values and trends for progressive iterations of the minimum set problem for target $=2.0 \times n$. In total, 44 additional subcatchments beyond those in the current Biodiversity Recovery Catchment system were needed to satisfy the target for all 23 assemblages. Values are recalculated after each iteration of the algorithm; (a) iteration 0, (b) iteration 15, (c) iteration 30, and (d) iteration 43. 


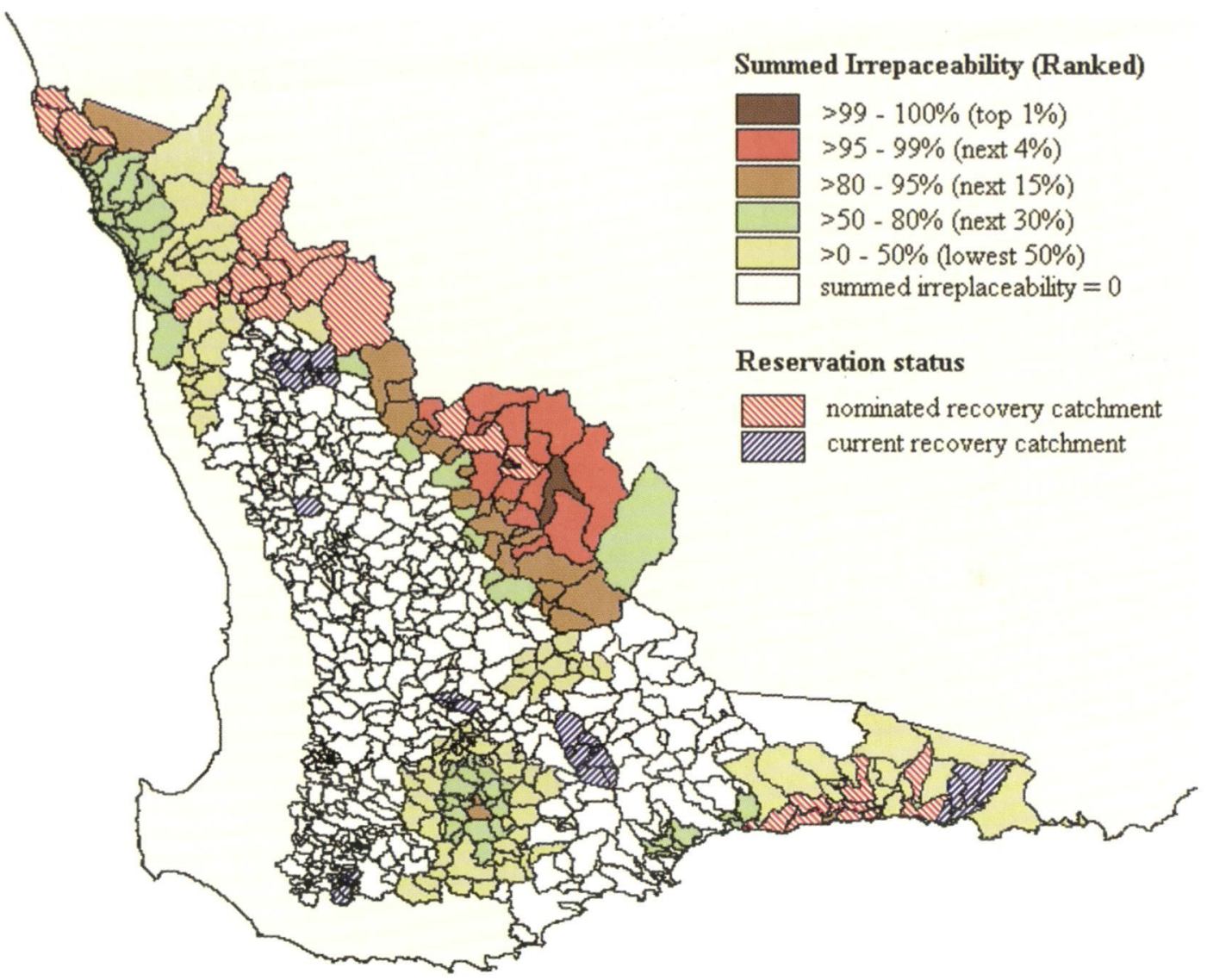

(c)

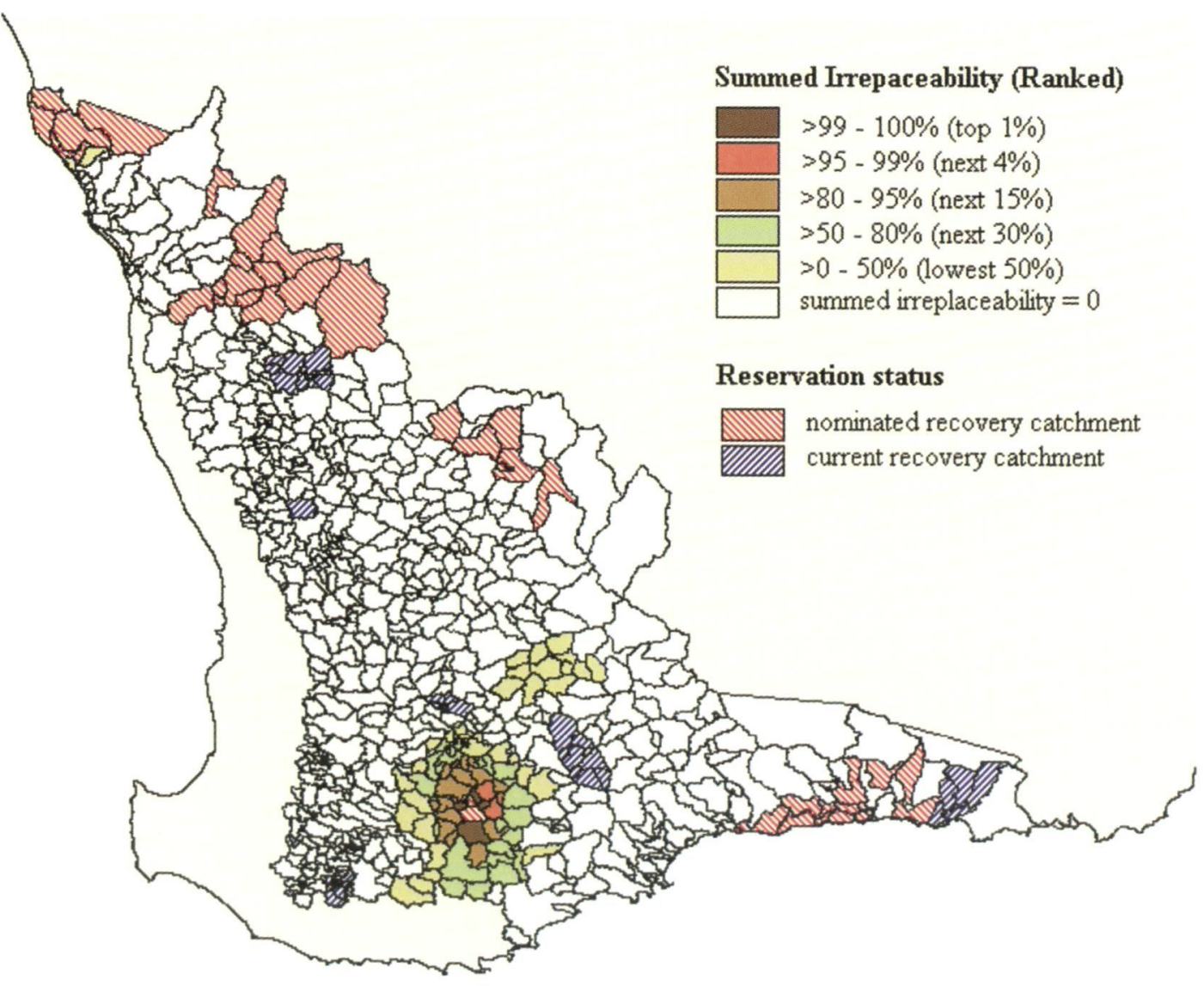

(d)

Summed Irrepaceability (Ranked) 
area of $41565 \mathrm{~km}^{2}$ added to the current system of Natural Diversity Recovery Catchments. Assuming stakeholders resolve that acquisition and maintenance cost constraints mean that only about double the number of subcatchments already protected in current recovery catchments can be considered economically feasible, the maximum achievable target is $2.0 \times n,(44$ additional subcatchments comprising an area of $24746 \mathrm{~km}^{2}$ ).

Although the trend in Figure 3 is approximately linear for both the number of subcatchments and area, extrapolation beyond a target equivalent to 3.0 $\times n_{j}$ is inappropriate. The reduction in area for the target $1.0 \times n$ relative to $0.8 \times n$ arises from the iterative nature of the algorithm and its interaction with the variable size of subcatchments, and sensitivity of the rank order of irreplaceability values to different targets (Warman et al., 2004).

Examples of the spatial patterning in selected subcatchments for targets $1.0 \times n, 2.0 \times n$, and $3.0 \times$ $n$ are shown in Figure 4 . The spatial configuration of selected subcatchments within and between targets is generally clustered. The qualitative consistency in areas selected suggests robust identification of core zones of conservation investment efficiency.
Figure 5 shows groupings of the derived minimum set of subcatchments proposed for the $2.0 \times n$ target, based on the hydrological basins in which they occur. Table 3 presents collapsed results for the sum of species richness for the proposed groupings, together with equivalent summary values for the current Natural Diversity Recovery Catchments. Full results are provided in Appendix 2. The current recovery catchments were found to contain negligible representation of species associated with Assemblages T1_2, T6, T7, W2, and W12. Assemblages T16, W3, W4, W10 and W11 had less than the $2.0 \times n_{i}$ target within current recovery catchments. The target was achieved independent of additional proposed subcatchments for assemblages T8a, T27_33, W1, W5, W6, W8, W9, W13, W14, W16, W17, W18 and W20.

With the addition of proposed recovery catchments, the $2.0 \times n$ target was only marginally achieved for assemblages T1_2, T6, T16, W2, and W3. Other assemblages had total summed species richness values ranging from $112 \%$ of $2.0 \times n$ for assemblage $\mathrm{W} 10$ to $2228 \%$ for the relatively ubiquitous assemblage, W6 (Table 3). Examination of Figure 5 and Appendix 1 reveals that, generally,

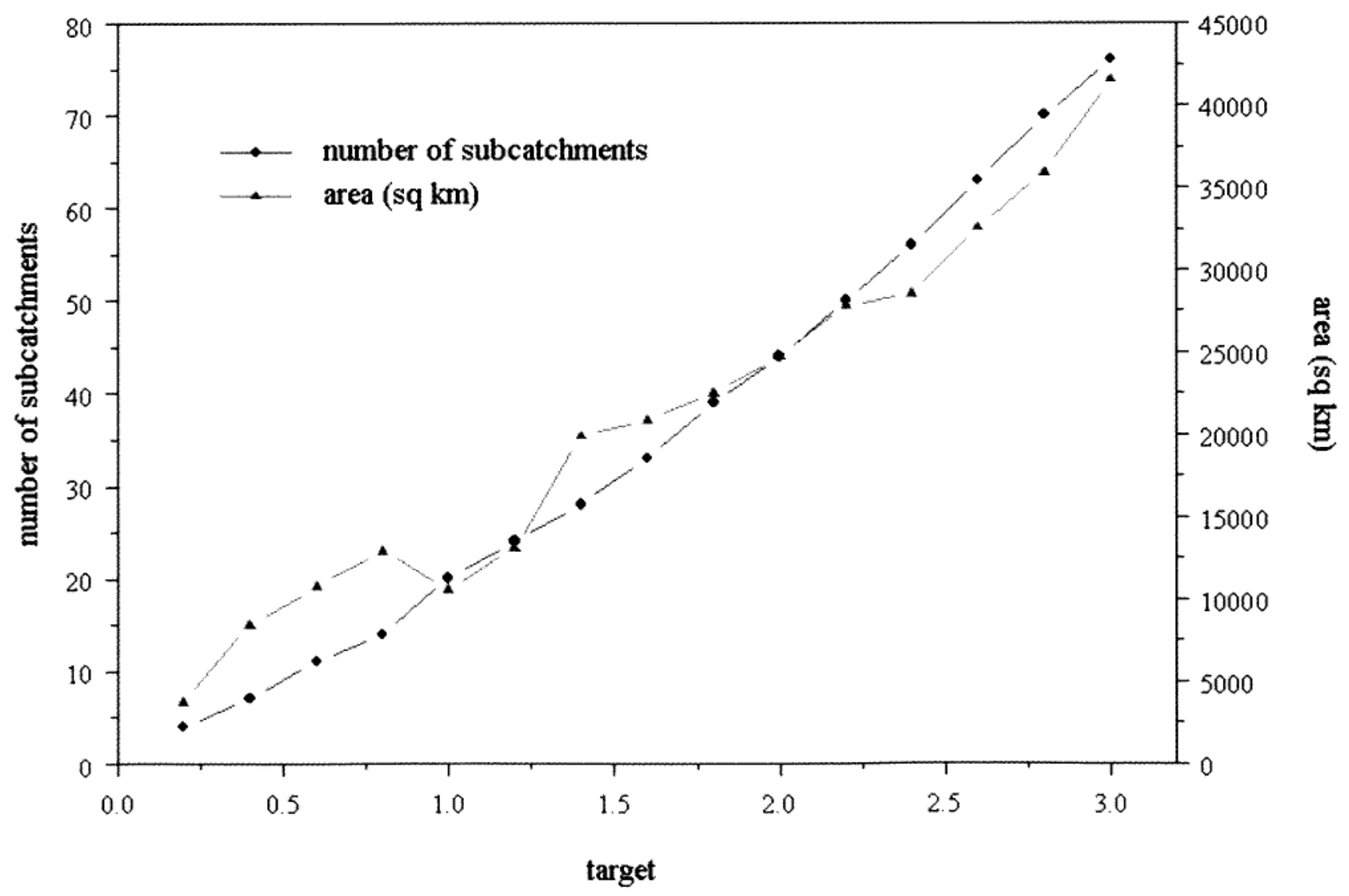

Figure 3 The minimum number of additional subcatchments and area needed to satisfy conservation targets ranging from $0.2 \times n$ to $3.0 \times n$, beyond that already protected in current recovery catchments. The number of subcatchments in current natural diversity recovery catchments is 46 . If the system's expansion was limited to doubling the number of subcatchments, a target of $2.0 \times n_{7}$ would be achievable. 
a recovery atchment svstem collectively comprising current and proposed subcatchments captured high richness centres for each assemblage. Exceptions were assemblage WI (where the target was principally achieved through moderate richness values associated with lake Bryde subcatchments) and Wt (where the target was made up from moderate richness values inferred within the current recovery catchments Drummond and Lake Warden, and the proposed catchments Esperance Coast, Greenough (Hutt) and Murchison)

An indication of progress toward target achievement with sequential addition of subcatchments to the current natural diversity recovery catchment system is shown in Figure 6. After the addition of 30 subcatchments, the drivers of the selection procedure were effectively restricted to assemblages T1_2, T6, T16, W2, W3 and W12. At the penultimate iteration, only assemblage T6 remained below the $2.0 \times n$, target. The interaction of progress in target achievement and summed irreplaceability is illustrated in Figure $2 \mathrm{~d}$, where the map corresponding to the penultimate iteration 43 shows priority for areas around the proposed Blackwood recovery catchment, coinciding with the richness maximum of assemblage T6 (Appendix 1).

The representation of all assemblages increased with the addition of selected proposed recovery catchments, although only marginally so for the geographically restricted assemblages T27_33 and W18, for which the current recovery catchment Muir-Unicup contained summed species richness values exceeding the $2.0 \times 11$ target

Generally, the extent to which assemblage-specific targets were excected at the conclusion of the selection procedure depended largely on the interplay between the number of species associated with an assemblage (11), its maximum subcatchment-specific richness value $(r)$, and its geographic distribution. Assemblages with less than $130 \%$ target achievement (Figure 6a) tended to be characterised by high $n$ relative to $r$, and/or restricted geographic distributions. Assemblages greatly exceeding the $2.0 \times n$ target were characteristically associated with low 11 relative to $r$ and/or ubiquitous distributions (Figure $6 b$ and 6c. Appendix 1).

\section{DISCUSSION}

The use of systematic reserve selection algorithms requires a number of methodological decisions to which results may be sensitive (Pressey and Logan, 1998; Prossey of al. 1999; Warman ot al. 2004). In malyses undertaken here, comment is warranted on decisions we made regarding (a) the biological data underpioning site selection; (b) units that act as candidate sites for selection; and (c) the setting of targets for each assemblage using summed species richness

A variety of methods can be used in spatial modelling of biological data. Among those that can be applied without direct consideration of underlying environmental gradients are lowess regression (Trexler and Travis, 1993), inverse distance weighted interpolation (Beckler et al., 2004), and kriging (Bolstad et al., 1998). Predictions that explicitly address environmental variables include expert opinion-based models (Van Horne and Weins, 1991) and statistical generalised linear (Lobo it al., 2004) or generalised additive (Guisan it al., 2002) models. For aquatic and terrestrial assemblages derived from the wheatbelt biological survey, Halse of al. (2004) and Mckenzie et al. (2004) related richness to environmental attributes using generalised linear models. The environmental attributes provided as candidate predictor variables in the modelling exercise included detailed physico-chemical attributes recorted at each sampling site. Because these detailed attributes have not been mapped throughout the study area, we could not apply model predictions to infer richness patterns.

We chose TINs to interpolate richness patterns because the method involves the simplest assumptions and provides transparency in the derivation of assemblage-specific subcatchment richness values (Appendix 1). Where interpolated surfaces clearly failed to discriminate areas of high and low species richness, we omitted assemblages from recovery catchment selection analysis. Nevertheless, we note that the interpolation procedure is a coarse predictor of landscape and subcatchment-scale trends and that further field sampling of the wheatbelt's biota is needed for more robust inference of spatial richness trends.

Limitations associated with the quality and resolution of mapped environmental attributes were not confined to detailed physico-chemical attributes. The presence and extent of native vegetation and wetlands are fundamental to the representation of terrestrial and aquatic biota in identified recovery catchments. Although spatial datasets describing the distribution of remmant vegetation and wetlands were avalable, we considered their naive use in analyses to be inappropriate. For wetlands, the spatial resolution of available data was regarded as inadequate because we knew of smaller important wetlands that were not included. For the terrestrial biota, the area of remnant vegetation within subcatchments provided no information on the presence or extent of any particular assemblage, and we considered its use in conditioning site selection would lead to unfounded confidence in the rigour of obtained results. 
(a)
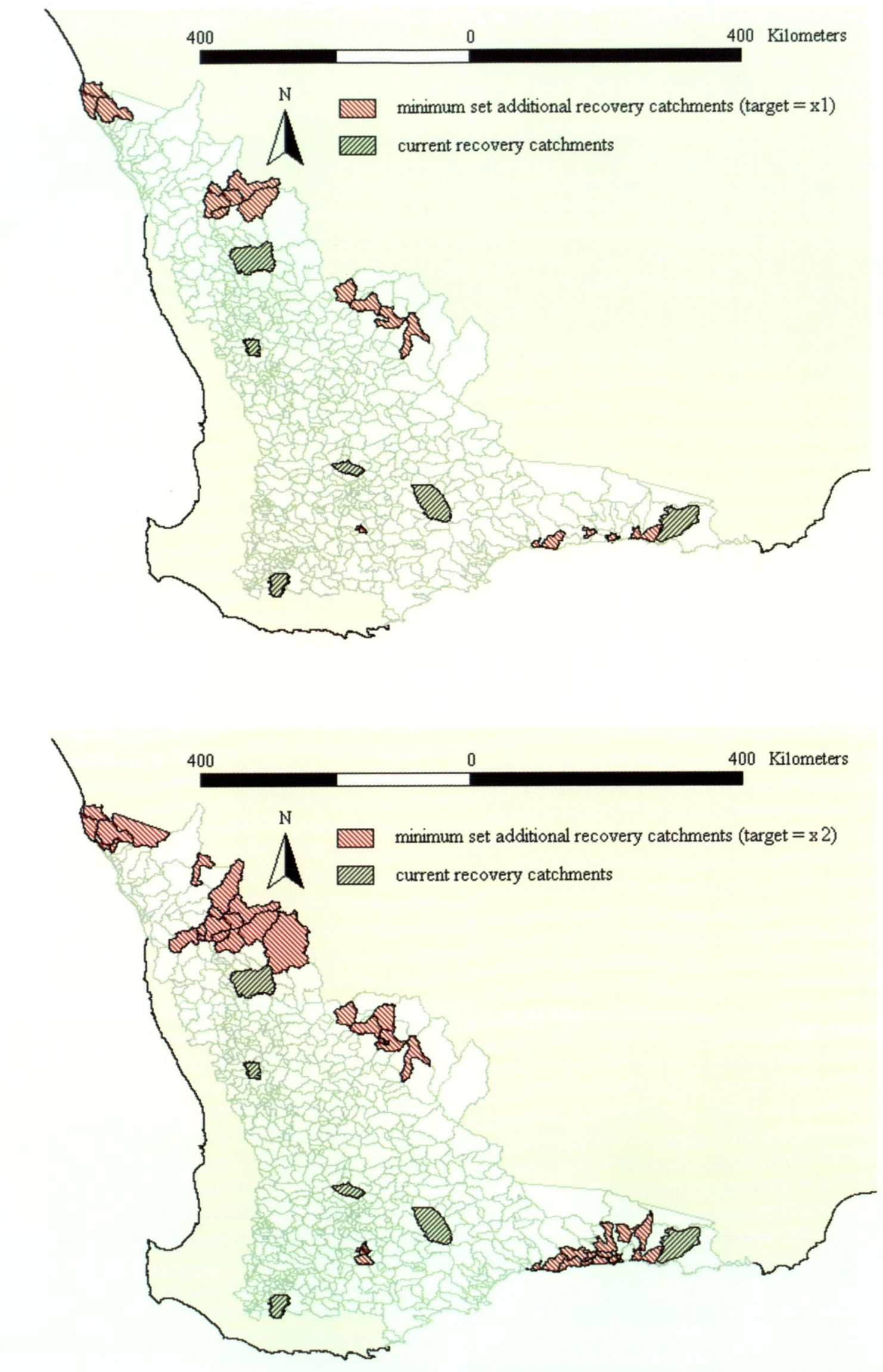

(b)

Figure 4 Maps of the minimum set of additional subcatchments needed to satisfy targets of (a) $1 \times n_{i,}$, (b) $2 \times n_{j,}$, and (c) $3 \times n_{i}$. Note that the qualitative pattern in the broad areas selected is consistent with varying targets. 

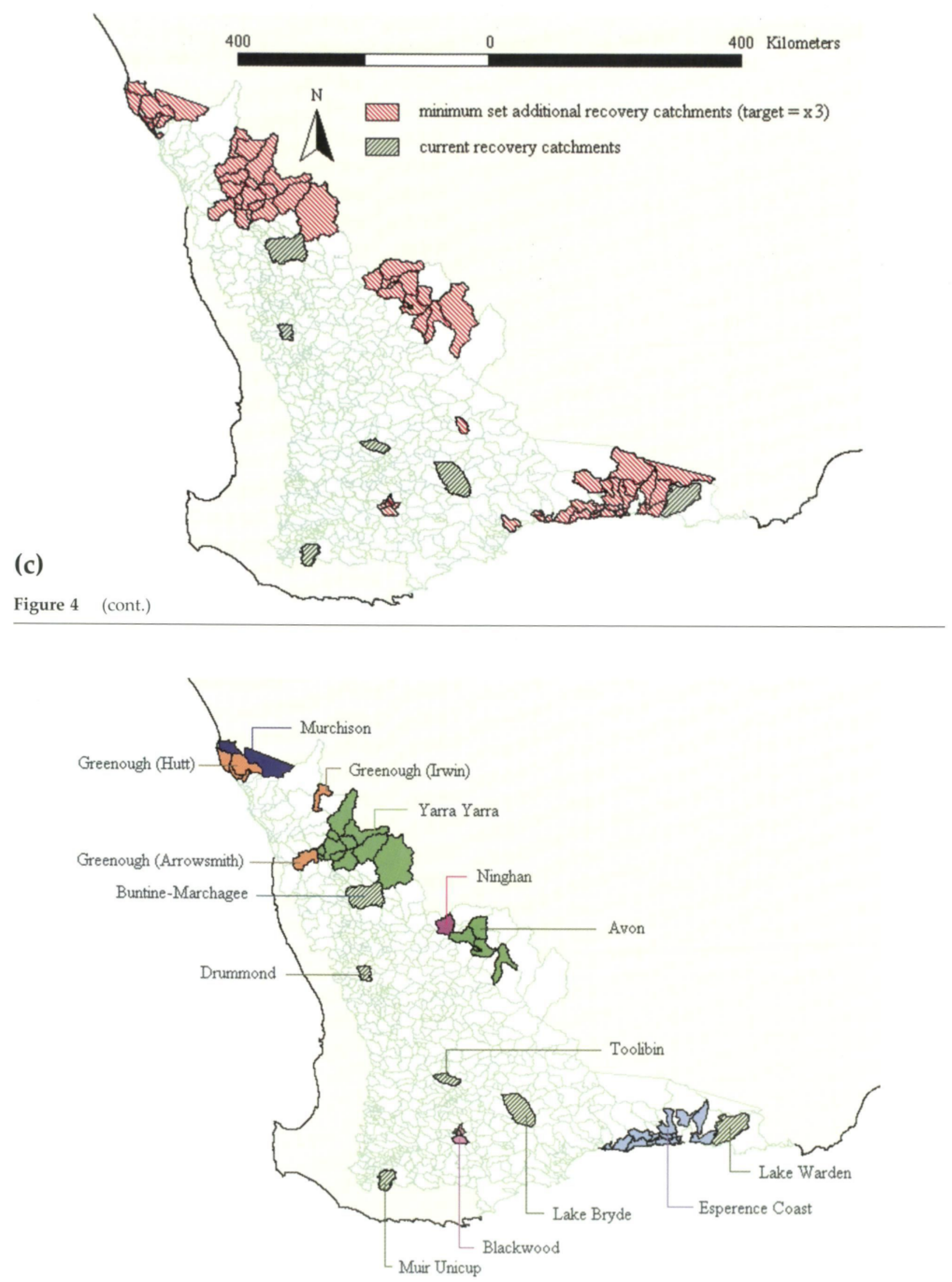

Figure 5 Map illustrating the location and grouping of current and proposed recovery catchment sites for the $2 \times n$. target. Proposed recovery catchments are grouped according to the hydrological basin in which they occur. For the spatially disjunct subcatchments selected within the Greenough basin, catchments are also used to describe groupings. Summed species richness values for current and proposed recovery catchments are summarised in Table 3. Full details are provided in Appendix 2. 
(a)

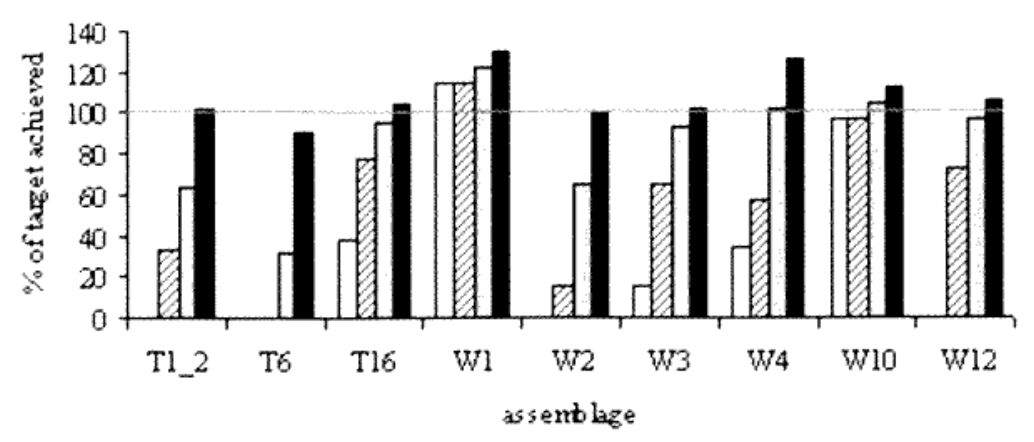

(b)

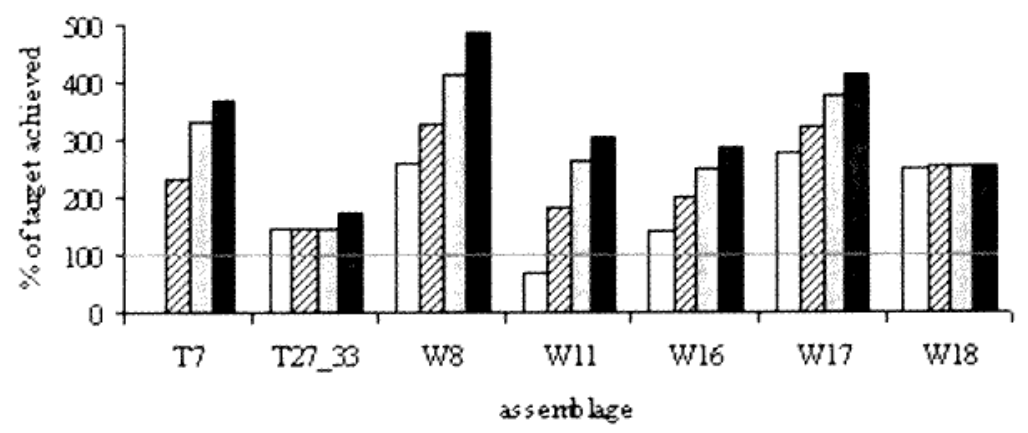

(c)

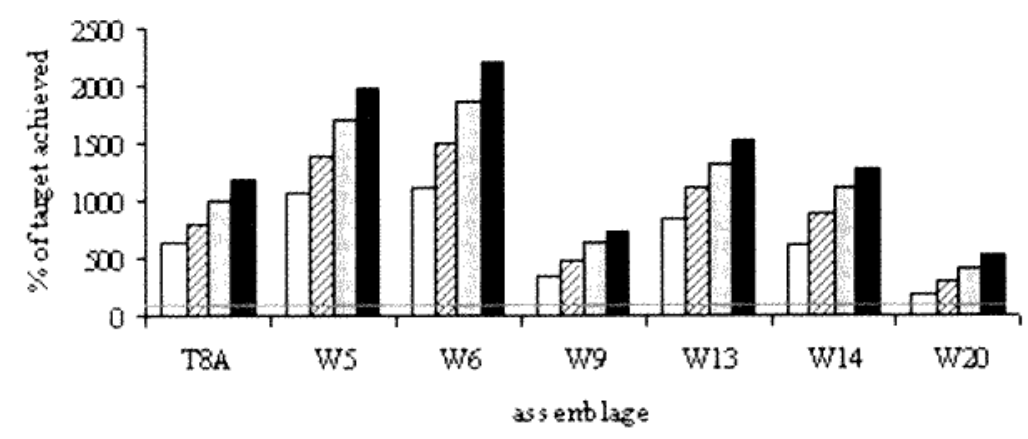

Figure 6 Iterative progress toward achievement of the $2.0 \times n$ target for each assemblage. Individual graphs show assemblages with (a) relatively low representation in the minimum set, (b) intermediate representation in the minimum set, and (c) high representation in the minimum set. The $100 \%$ target equivalent to $2.0 \times n$ is shown by the horizontal red line. Each graph depicts \% of target achieved after iteration 0 (white), iteration 15 (hatched), iteration 30 (grey), and iteration 43 (black). These iteration steps can be cross-referenced to summed irreplaceability maps shown in Figure 2.

There is no universal theoretical basis for deciding the size or shape of candidate sites for systematic conservation planning (Stoms, 1994). We used subcatchments on the assumption that they provide a pragmatic and hydrologically appropriate unit of management in the context of dealing with the threat of salinity. The effectiveness of the proposed recovery catchment system will be compromised to the extent that subcatchment boundaries are incongruent with the spatial scale of hydrogeological processes driving dryland salinity (Ferdowsian et al., 1996; Shao et al., 1999).

The summing of an assemblage's richness values for all selected units implicitly assumes that subcatchments are independent and additive. The extent to which the full set of species that comprise individual assemblages is represented in proposed recovery catchments is sensitive to the assumption of independence. Species lists for adjacent subcatchments are more likely to be similar than predicted by chance. That is, species composition 
throughout the study area is likely to be spatially autocorrelated (Legendre, 1993). In the presence of strong spatial autocorrelation, the clumped distribution of proposed recovery catchments identified in analyses undertaken here will tend towards a distinct over-representation of some species and under-representation of others.

The effect of autocorrelation could be addressed by stipulating a minimum threshold distance between selected sites beyond which subcatchments can be regarded as compositionally independent. However, the treatment of autocorrelation in this way would lead to fragmentation of the recovery catchment system (Price of al., 1995; Possingham et al., 2000). Limitations in the software we used here precluded this approach, although recent advances in analytical tools may be used to accommodate the incorporation of spatially explicit trade-offs involving fragmentation and autocorrelation in conservation planning (McDonnell et al., 2002; Cabeza it al., 2004).

With respect to the assumption of additivity, it is important to recognise that the interpolation procedure we used implies that the inferred richness of a subcatchment is insensitive to the size of the subcatchment, the number or total area of wetlands, and the extent of vegetation cover contained therein. That is, it is implicitly assumed that the plot size and sampling intensity emploved in the wetland and terrestrial surveys (Halse it al., 2004; Mckenzie et al., 2004) provided species richness results that in all cases approached the asymptote of each assemblage's species-area curve (Thompson and Withers, 2003).

Scale effects associated with variability in the area and number of subcatchments that make up current and proposed Natural Diversity Recovery Catchments (Figure 5, Appendix 2) may cause substantial distortions in effective assemblage representation (Pressey and Logan, 1994). Variability in the size of candidate sites and the omission of any direct consideration of the distribution of aquatic and terrestrial habitats within subcatchments have important implications for site selection using targets formulated as summed species richness. For example, although the Drummond Recovery Catchment has an area of $360 \mathrm{~km}^{2}$, it comprises only one subcatchment and contributes relatively little to the achievement of assemblage-specific targets. The comparably sized Muir Unicup Recovery Catchment comprises 11 subcatchments and makes considerably greater contribution to the representation of a suite of assemblages (Table 3, Appendix 2). The smallest subcatchment among current and proposed recovery catchments was $2.0 \mathrm{~km}^{2}$ (part of BuntineMarchagee) and the largest $3843.5 \mathrm{~km}^{2}$ (in the proposed Yarra Yarra recovery catchment; see Appendix 2). Very small subcatchments may not be ecologically viable (Possingham et al., 2000; McDonnell ef al, 2002; Warman ot al., 2004), while it may not be operationally feasible to effectively manage salinisation in larger subcatchments.

Some features of interest may be less critical than others when consideration is given to conservation status beyond study area boundaries. The biota of the wheatbelt has been described as transitional (Hopper, 1979; Mckenzie of al., 2004), including diffuse elements bevond the study area that are more strongly associated with the north, inland east, coastal west and coastal south. Given that extensive tracts of native vegetation remain in the pastoral zone to the east of the study area, there may be partial redundancy in areas selected in the minimum set solution. For example, assemblage T1_2 comprises species associated with semi-arid and arid woodlands (McKenzie et al., 2004). If it can be verified that reserves and remnants in the pastoral zone adequately represent this assemblage, the proposed recovery catchments Avon and Ninghan may be unnecessary (see Table 3).

Analyses can be extended to incorporate consideration of variability in the size of candidate sites and non-critical features. As an example, we explored stability in the spatial configuration of potential recovery catchments after omitting assemblage $\mathrm{T} 1$ 2 from analyses and restricting candidate sites to subcatchments ranging in area from $50 \mathrm{~km}^{2}$ to $1000 \mathrm{~km}^{2}$. For the sake of illustration, a more or less arbitrary threshold of $50 \mathrm{~km}^{2}$ was set for defining an ecologically viable area. Subcatchments larger than $1000 \mathrm{~km}^{2}$ might represent areas where management costs are prohibitive. The minimum set of subcatchments selected for the $2.0 \times 11$ target (Figure 7) was largely congruent with the spatial configuration of previous analyses (Figure 5). A notable contrast was non-selection of the Avon and Ninghan proposed recovery catchments as a consequence of the assumption that assemblage T1_2 was sufficiently conserved elsewhere. Also, the exclusion of smaller subcatchments in the Muir-Unicup recovery catchment was compensated by selection of additional areas to the immediate east and north (Figure 7 ).

Collectively, these methodological shortcomings mean that the results of analyses can only be used as a guide for the identification of areas that would best complement current Natural Diversity Recovery Catchments in the representation of wheatbelt assemblages. Results need to be regarded as indicative and relative rather than absolute or prescriptive, in terms of both specified targets and the exact spatial location of the best set of proposed recovery catchments. Nevertheless, the consistency in the qualitative pattern of selected sites for varying targets (Figure 4 ) suggests core areas of efficiency in conservation investment. 


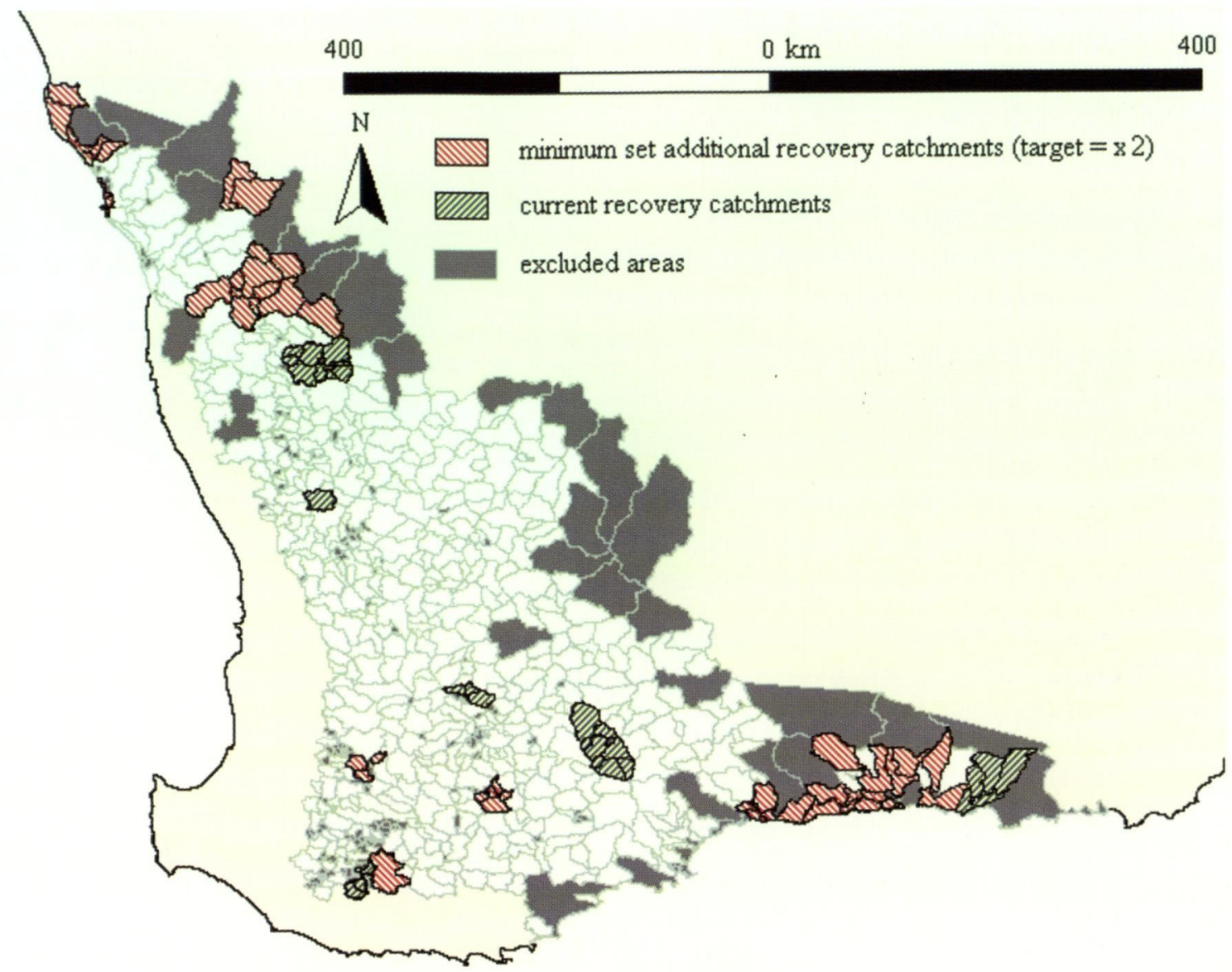

Figure 7 Map of the minimum set of additional subcatchments needed to satisfy the $2 \times n_{j}$ target after omitting assemblage T1_2 from the analysis and restricting candidate sites to subcatchments ranging in area from 50 $\mathrm{km}^{2}$ to $1000 \mathrm{~km}^{2}$. See text for details.

Table 4 Assemblages and areas requiring particular diligence in field reconnaissance and verification. According to analyses undertaken for $2.0 \times n_{i}$, listed assemblages either achieved less than $200 \%$ of the target or contained $\geq 50 \%$ of the sum of species richness represented in only one current or proposed recovery catchment. Black squares indicate recovery catchments where the analysis indicated high $(\geq 50 \%)$ contribution to achievement of the $2.0 \times n_{j}$ target. Grey squares indicate moderate $(25-49 \%)$ contribution, and white squares indicate relatively low $(<25 \%)$ contribution.

\begin{tabular}{|c|c|c|c|c|c|c|c|c|c|c|c|c|}
\hline Recovery Catchment & T1_2 & T6 & T7 & T16 & T27_33 & W1 & W2 & W3 & W4 & W10 & W12 & W18 \\
\hline \multicolumn{13}{|l|}{ Current } \\
\hline \multicolumn{13}{|l|}{ Buntine-Marchagee } \\
\hline Drummond & & & & & $\square$ & $\square$ & & & $\square$ & & & \\
\hline Lake Bryde & & & & & & $\mathbf{a}$ & & & & 口 & & \\
\hline Lake Warden & & & & 语 & & & & $\square$ & $\square$ & & & $\square$ \\
\hline Muir Unicup & & & & & 口 & & & & & & & $\mathbf{a}$ \\
\hline \multicolumn{13}{|l|}{ Toolibin } \\
\hline \multicolumn{13}{|l|}{ Proposed } \\
\hline Avon & 㫜 & & $\square$ & & & & & & & & & \\
\hline Blackwood & & 䞒 & & & 1) & $\square$ & & & & & & \\
\hline Esperence Coast & & & & $\mathbf{\square}$ & & & & $\mathbf{a}$ & 닐 & $\square$ & & $\square$ \\
\hline Greenough (Arrowsmith) & & & & & & & $\square$ & & & & $\square$ & \\
\hline Greenough (Hutt) & & 冓 & 대 & & & $\square$ & 붕 & & 리 & & & \\
\hline Greenough (Irwin) & & & $\square$ & & & & $\square$ & & & & $\square$ & \\
\hline Murchison & & $\square$ & $\square$ & & & & $\square$ & & $\square$ & & & \\
\hline Ninghan & $\square$ & & $\square$ & & & & & & & & - & \\
\hline Yarra Yarra & 簐 & & $\mathbf{\theta}$ & & & & & & & & $\mathbf{E}$ & \\
\hline
\end{tabular}


Field reconnaissance and verification is necessary, for which the results in Table 3 and Appendix 2 provide a basis for assessment. Of particular importance in field reconnaissance are assemblages for which targets are only marginally achieved or for which representation is more or less restricted to one recovery catchment. Table 4 lists assemblages where either less than $200 \%$ of the $2.0 \times n_{i}$ target was achieved or only one current or proposed recovery catchment contains $\geq 50 \%$ of the sum of species richness predicted to be represented.

Independent of issues associated with the methods employed here, the identification of recovery catchments necessarily involves broader consideration of ecological issues, social acceptability and economic feasibility. Although analyses focussed on assemblage-specific targets equivalent to $2.0 \times n_{i}$, there is little basis to any assertion that this level of representation is ecologically adequate (Burgman and Lindenmayer, 1998). The principal focus of algorithms for systematic selection of conservation areas is efficient allocation of scarce conservation resources for defined representation targets. In practice, identification of conservation areas needs to go beyond simple representation and consider connectivity and replication to promote long-term persistence of diversity (Ferrier, 2002). Only recently have researchers sought to extend methods to explicitly incorporate persistence (Cabeza and Moilanen, 2001; Faith et al., 2001; Carroll et al., 2003).

Although dryland salinity is a key threat to the persistence of the wheatbelt's biota, no account of the spatial distribution of salinisation trends is made in analyses presented here. Lawler et al. (2003) integrated representation and vulnerability in a systematic reserve selection problem through parallel mapping of site irreplaceability and vulnerability, and by incorporating vulnerability scores into the selection algorithm. We chose not to treat the threat of salinity directly because of the magnitude of uncertainty surrounding predictions of future salt affected areas (Ferdowsian et al., 1996; Evans, 2000), and the paucity of research addressing the physiological and ecological response of species and assemblages (Greenway and Munns, 1980; Vartapetian and Jackson, 1997) although this is being remedied (see Cramer and Hobbs, 2002; McKenzie et al., 2003; Pinder et al., 2005). It is important that managers and planners consider the best available information on the extent of salinity and the susceptibility of the biota when finalising decisions about which areas might best serve as recovery catchments (Kristjanson and Hobbs, 2001; Pannell, 2001).

Taxonomically, the wheatbelt survey comprises a greater breadth than typical datasets used to identify conservation areas. The terrestrial survey included vascular plants, reptiles, frogs, mammals and arachnids (McKenzie et al., 2004). The wetland survey recorded vascular plants, invertebrates and waterbirds (Halse et al., 2004). Therefore, deficiencies associated with selecting conservation areas on the assumption that ad-hoc collections for limited taxa provide effective surrogacy for all biota (Ferrier and Watson, 1997; Balmford, 1998; McKenzie et al., 2000; Moritz et al., 2001) are less pervasive in this application. However, it is important to note that singletons comprised $33 \%$ of the terrestrial species recorded in the survey and $34 \%$ of aquatic species, and were excluded from the classification analyses used to generate assemblages. The limitations of surrogate approaches to conservation planning and the tangential treatment of diversity persistence in reserve selection algorithms suggest planners and managers need to treat minimum set solutions conservatively.

Systematic conservation planning for the wheatbelt need not be limited to representation of identified assemblages. The conservation objectives of the Salinity Investment Framework (Department of Environment, 2003) address three asset types: (i) rare species, (ii) rare communities, and (iii) areas that provide good representative samples of biodiversity. The analyses undertaken here relate most directly to 'good representative samples of biodiversity'. Other conservation asset types can be explicitly incorporated into the analysis by inclusion in a subcatchment-by-assets matrix and the identification of asset-specific targets beyond assemblages. It is important to note that the minimum set of subcatchments selected on the basis of richness trends for wheatbelt assemblages is unlikely to be consistent with analyses that include additional conservation assets (Pressey et al., 1999; Warman et al., 2004). Where the number of additional assets is few, an alternative is to manually extend the recovery catchment system post-hoc. This approach would be necessary for conservation features for which distributional data are sparse or notably biased, including the assemblages T3_5, W7 and W21 that we omitted from our analyses.

While capable of providing near-optimal solutions for defined representation targets, heuristic algorithms are especially advantageous in exploring alternative configurations for conservation areas that may lead to better economic and social outcomes at the cost of only small losses in efficiency (Pressey et al., 1996; McDonnell et al., 2002). In particular, the iterative display of mapped irreplaceability values (Figure 2) allows stakeholders to explore flexibility in real time through identification of alternative sites where minimum set solutions are regarded as impractical (Pressey, 1998). For example, for the problem of 
identifying recovery catchments, alternative smaller subcatchments may be found to replace larger subcatchments considered too cumbersome or expensive to manage, possibly without a net increase in the area selected. Similarly, the various issues canvassed in this discussion can be explored, including ecological adequacy and connectivity, redundancy, and salinity risk.

Constraints in the acquisition and coverage of biological data inevitably compromise regional conservation planning. The analyses undertaken here were underpinned by relatively coarse-scale data (although much better and more taxonomically comprehensive than usuaaly available) but the results provided by the heuristic algorithm identified robust core zones of investment efficiency for the representation of wheatbelt assemblages across a range of conservation targets. The insights afforded by the survey data and analyses within this paper provide a distinctly better basis for the allocation of scarce resources than the ad-hoc or opportunistic approach to selection of conservation areas typically used in the past (Pressey et al., 1993; Pressey, 1995; Burgman and Lindenmayer, 1998).

\section{ACKNOWLEDGEMENTS}

Bob Pressey (New South Wales Department of Environment and Conservation) made available the software, C-Plan. We thank Rick Tomlinson and Trevor Smales from the Department of Conservation and Land Management for preparation of assemblage TINs. The structure and content of the manuscript benefited from the comments of Bob Pressey and Mark Burgman. Funding for this work was provided as part of the State Salinity Strategy.

\section{REFERENCES}

Anonymous. (1996). Western Australian salinity action plan. Government of Western Australia, Perth.

Balmford, A. (1998). On hotspots and the use of indicators for reserve selection. Trends in Ecology and Evolution 13: 409.

Beckler, A.A., French, B.W. and Chandler, L.D. (2004). Characterization of western corn rootworm (Coleoptera: Chrysomelidae) population dynamics in relation to landscape attributes. Agricultural and Forest Entomology 6: 129-139.

Bedward, M., Pressey, R.L. and Keith, D.A. (1992). A new approach for selecting fully representative reserve networks: Addressing efficiency, reserve design and land suitability with iterative analysis. Biological Conseroation 62: 115-125.

Belbin, L. (1992). Comparing two sets of community data: A method for testing reserve adequacy. Australian Journal of Ecology 17: 255-262.

Bolstad, P.V., Swank, W. and Vose, J. (1998). Predicting
Southern Appalachian overstory vegetation with digital terrain data. Landscape Ecology 13: 271-283.

Burgman, M. A., Ferson, S. and Akcakaya, H. R. (1993). Risk assessment in conservation biology. Chapman and Hall, London.

Burgman, M.A. and Lindenmayer, D.B. (1998). Conservation biology for the Australian environment. Surrey Beatty \& Sons, Sydney.

Cabeza, M., Araujo, M.B., Wilson, R.J, Thomas, C.D., Cowley, M.J.R. and Moilanen, A. (2004). Combining probabilities of occurrence with spatial reserve design. Journal of Applied Ecology 41: 252-262.

Cabeza, M. and Moilanen, A. (2001). Design of reserve networks and the persistence of biodiversity. Trends in Ecology and Evolution 16: 242-248.

Carroll, C., Noss, R.E., Paquet, P.C. and Schumaker, N.H. (2003). Use of population viability analysis and reserve selection algorithms in regional conservation plans. Ecological Applications 13: 1773-1789.

Cramer, V.A. and Hobbs, R.J. (2002). Ecological consequences of altered hydrological regimes in fragmented ecosystems in southern Australia: impacts and possible management strategies. Austral Ecology 27: 546-564.

Department of Environment. (2003). Salinity investment framework interim report - phase 1. Salinity and Land Use Impacts Series 32. Department of Environment, Perth.

ESRI. (1992). ArcView GIS 3.2a. Environmental Systems Research Institute, Redlands CA.

Evans, F. (2000). Land Monitor salinity risk prediction. Dumbleyung and Mt Barker regions. CMIS Task Report 2000/45. CSIRO, Floreat.

Faith, D.P., Walker, P.A. and Margules, C.R. (2001). Some future prospects for systematic biodiversity planning in Papua New Guinea - and for biodiversity planning in general. Pacific Conservation Biology 6: 325-343.

Ferdowsian, R., George, R., Lewis, F., McFarlane, D., Short, R. and Speed, R. (1996). The extent of dryland salinity in Western Australia. In Proceedings of the $4^{\text {th }}$ National Workshop on the Productive Use and Rehabilitation of Saline Lands, Albany, March 1996: 8889.

Ferrier, S. (2002). Mapping spatial pattern in biodiversity for regional conservation planning: where to from here? Systematic Biology 51: 331-363.

Ferrier, S., Pressey, R.L. and Barrett, T.W. (2000). A new predictor of the irreplaceability of areas for achieving a conservation goal, its application to real world planning, and a research agenda for further refinement. Biological Conservation 93: 303-325.

Ferrier, S. and Watson, G. (1997). An evaluation of the effectiveness of environmental surrogates and modelling techniques in predicting the distribution of biological diversity. Environment Australia, Canberra.

Frietag, S., Nicholls, A.O. and van Jaarsveld, A.S. (1998). Dealing with established reserve networks and incomplete distribution data sets in conservation planning. South African Journal of Science 94: 79-86.

Garey, M.R. and Johnson, D.S. (1979). Computers and intractability. A Guide to the theory of NP-completeness. WH Freeman, San Francisco. 